\title{
Conceptual design of a natural fibre-reinforced composite automotive anti-roll bar using a hybrid approach
}

\begin{abstract}
In this study, a hybrid conceptual design approach is introduced in the development of natural fibre-reinforced composite automotive components. A combination of quality function deployment for environment, theory of inventive problem solving and blue ocean strategy is applied where the important requirements in terms of the material characteristics, function specification, forces and failure mode analysis and geometry specification are considered. A new conceptual design for a composite automotive anti-roll bar was computed in consideration of restrictions from the natural fibre properties, which are different to those of the traditional material, which is alloy steel. The design that gained the highest score (3.7\%), and was thus chosen as the final conceptual design, was the one with tapered arms reinforced with a corner rib to stiffen the structure of the design. The new design could solve the problem of stress concentration, which is a major cause of failure of the automotive anti-roll bar. Based on strategy canvas, comparison of the natural fibre-reinforced composite anti-roll bar with carbon fibre composite and a steel anti-roll bar showed that the natural fibrereinforced composite anti-roll bar has more advantages where it satisfied almost all the design requirements with respect to customers and environment. However, the final conceptual design has to undergo several modifications for assembly and manufacturing purposes, which will be performed in a further study.
\end{abstract}

Keyword: Conceptual design; Natural fibre-reinforced composites; Automotive anti-roll bar 